\title{
GREGORIO PECES-BARBA: HOMBRE DE LEYES, HOMBRE DE ESTADO. IN MEMORIAM
}

\author{
Elías Díaz \\ Universidad Autónoma de Madrid
}

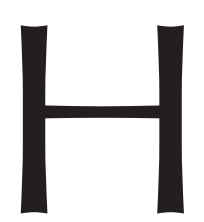

ombre de leyes, jurista conocedor a fondo del derecho, también con destacada práctica de la abogacía (recordado en muy conflictivos procesos políticos bajo/contra la dictadura), catedrático de Filosofía del derecho, estudioso pionero entre nosotros de la historia y realidad de los derechos humanos, rector-fundador de la Universidad Carlos III, siempre atento al trabajo de los estudiantes y eficaz director de sus equipos docentes e investigadores. Hombre de Estado, quiero decir con visión y sentido del Estado, político activo contra el régimen franquista, después en democracia diputado socialista, uno de los siete «padres» de la Constitución de 1978, gran defensor del Estado social y democrático de derecho, de sus instituciones jurídico-políticas, del Parlamento (fue presidente del Congreso de los Diputados entre 1982-1986), de las rectas funciones del poder ejecutivo y del poder judicial sin las cuales y su correlativa sociedad civil no hay democracia posible.

Pero ya todos conocen que G. PECES-BARBA, nuestro buen amigo y compañero, tanto en las líneas básicas del socialismo democrático como en las tareas de profesor e intelectual en la Universidad, murió el pasado 24 de julio de 2012. Ocurrió en la ciudad de Oviedo, en el Hospital Central de Asturias en cuya «Unidad de vigilancia intensiva» había sido internado al advertir —en Ribadesella, donde pasaba largas temporadas - cómo se agravaban algunas de las dolencias renales y cardiovasculares que le venían afectando de manera muy especial en los últimos tiempos. Allí en el pequeño reducto de dicha «Unidad de vigilancia intensiva» le visité muy pocos días antes, el jueves 19 de julio. Se alegró al verme aparecer. A pesar de todo, ese día se encontraba algo mejor. Estaba lúcido y tranquilo, incluso irónico, en la que por desgracia vendría a ser ya nuestra última conversación. Permítaseme aquí esta evocación personal en el comienzo de estas notas como trasunto de su final estado de ánimo y como señales para nuestra común memoria.

En esa mi visita al verle allí tan apacible metido en su acogedora cama, si bien conectado a diversos aparatos médicos, le insté directamente y sin más a que tenía que ponerse bueno enseguida y salir pronto de tan hospitalario lugar. Que con lo que teníamos encima (la famosa «prima de riesgo» subiendo y subiendo y la moral ciudadana cayendo y cayendo), hacía él mucha falta fuera, que -le espeté- «no olvides que tu eres un hombre de Estado», que en consecuencia por lo que dicen algunos -le sonreí con cierta sorna- «también a ti te cabe el Estado en la cabeza». Captó inmediatamen- 
te la indirecta referencia y, asimismo sonriendo, me contestó marcando la diferencia: «Sí, pero a mí es el Estado bueno, el Estado democrático». Luego bajando el tono se lamentó de que las enfermeras se habían olvidado de afeitarle y de que por ello estaba con esa barba de días. No era para tanto pero se lo rebatí: «Mejor, así ahora pareces de verdad un intelectual de izquierdas, barbado y no tan afeitadito y aseado como vas siempre». Se sonreía otra vez, pero seguía protestando de la rigidez de las mencionadas enfermeras porque no le dejaban hacer nada de lo que él quería (posiblemente comer más y otras cosas). Le apremié, repelente yo, aduciendo nuestros debates iusfilosóficos sobre la importancia y necesidad o no de la obediencia a las normas, puntualizándole que allí las enfermeras eran las celantes de las normas, de las nomoi (más válido sin duda tal aserto para diálogos de la Grecia clásica que de la rescatada actual). No parecía muy convencido pero cambiamos a otras cuestiones más personales, durante el tiempo permitido todavía para una visita en esa unidad especial, tiempo algo ampliado por las amables vigilantas dados mis buenos consejos al disidente, desobediente y (poco) paciente. Así seguimos platicando y mirándonos —ése es mi recuerdo final— para una despedida que en mí era esperanzada pero, a la vez, temerosa de lo que tristemente ocurriría de modo inesperado, el martes siguiente, breves días después.

Ahora Gregorio ya no está. Por desgracia hemos perdido al amigo que por fortuna hemos tenido (en mi caso desde hace casi cincuenta años), amigo fraterno, yo hermano mayor, con todos los problemas ínsitos en la fraternidad. Hoy todos sabemos de ciertos intelectuales de los que con razón se dice que «están de más»; en cambio, nuestro amigo siempre estará entre los que se «echan de menos». Quedan los recuerdos, las huellas, los libros, las ideas, los otros comunes amigos (concordantes o discrepantes con él). En definitiva, todo lo que de algún modo nos permite seguir siempre contando con los que serían sus juicios y actitudes ante también los más o menos nuevos o retornados problemas. Asimismo de los que, tras su muerte, están ocupando el primer plano de la más urgente y acuciante actualidad y/o de la más profunda y decisiva realidad política y social. Pero ahí estará —ya que no sus consultas y opiniones directas - siempre del profesor la necesaria referencia de fondo y las aplicaciones concretas de su filosofía jurídica y política.

\section{DERECHOS HUMANOS Y ESTADO DE DERECHO}

Es desde esta su dimensión política e intelectual desde la que debe destacarse cómo la preocupación en la lucha por los derechos humanos y la consiguiente consideración crítica (no indiscriminada) del poder radicado en las instituciones públicas (el derecho y el Estado) constituyen —creo- los dos (tres) ejes centrales y más constantes - siempre aunando a lo anterior los valores de la ética y la justicia- de esa su filosofía jurídica, moral y política. Resaltaría enseguida en el conjunto de estos básicos elementos la aspiración «totalizadora» que —creo- le caracteriza. $\mathrm{O}$, por decirlo en términos más cercanos y menos comprometidos, su permanente preocupación por la coherencia interna, por la sistematicidad de las realidades y los conceptos (derechos humanos e instituciones públicas) que forman parte de aquella.

Especialmente como jurista, en el talante intelectual de G. PECES-BARBA cabe siempre apreciar esa su pretensión de coherencia y sistematicidad. Y vinculado a ello, 
como profesor de filosofía jurídica, moral y política, estaría esa su diferenciación entre valores, principios y derechos de raíz rigurosamente racional (adecuada por fuerza a la realidad). Crítico tenaz del iusnaturalismo, sus posiciones axiológicas se manifestaban cercanas a un normativismo crítico y realista o al, por él denominado, «positivismo corregido» (sobre ello, su Diez lecciones sobre Ética, Poder y Derecho, obra publicada en 2010 revisando lecturas y trabajos anteriores, en una trayectoria de cincuenta años a modo de resumen de su pensamiento. $\mathrm{Y}$ antes las contestaciones a la muy completa y aguda entrevista hecha por M. ATIENZA y J. RuIZ MANERO, publicada en Doxa, núm. 31, 2008).

El teórico aplicó a la política práctica y en momentos decisivos esas sus «señas de identidad». En su obra sobre La elaboración de la Constitución de 1978, el profesor rememora diez años después (Centro de Estudios Constitucionales, 1988) las tareas del diputado socialista PECES-BARBA junto a cada uno de los siete ponentes encargados de redactar - con los adecuados apoyos externos, por supuesto- el texto constitucional que tras la Ponencia, pasaría a revisión y aprobación en la correspondiente Comisión y en el Pleno del Parlamento para finalmente ser sometido al referéndum de la soberanía popular. En los debates de entonces, en sus intervenciones constituyentes, y también después en esa genética rememoración, quedan patentes los grandes esfuerzos, yo diría que hasta los «sufrimientos», de G. PECES-BARBA y su «desesperación» ante las incomprensiones de algunos, por lograr en la naciente Constitución una estructuración y una articulación coherente y rigurosa, incluso en el lenguaje, de acuerdo con las exigencias analíticas de la ciencia jurídica y, desde ahí, en cuanto objetivo de dicha totalización, asimismo con la filosofía del derecho como teoría de la justicia y con la filosofía política.

Retomando así, como quedó indicado desde el inicio de estas páginas, ese lugar preeminente para, por un lado, el poder (realidad) y, por otro, los derechos humanos y las instituciones públicas (racionalidad) como categorías propias de la interrelacionada filosofía política y jurídica del durante largos años rector de la Universidad Carlos III de Madrid, sobre ellas se articulan básicamente las dos grandes dimensiones que, siempre en potencial conflicto, identifican la posición que, por mi parte, suelo yo calificar como «realismo crítico». Por un lado, el del realismo, la concepción normativa, pluralista y con «textura abierta» del ordenamiento jurídico, de la validez del derecho — esto es lo decisivo - fundada en el poder: «hecho fundante básico» lo denomina aquél. Me parece que en G. PECES-BARBA ese poder no se refiere tanto al poder social (economía incluida) —así lo vería yo— - sino más bien al que después se institucionaliza desde ahí, como poder político, en el Estado. Sus libros Libertad, poder, socialismo (1978) o su Introducción a la Filosofía del Derecho (1983), ilustran con detalle sobre esa rigurosa pero no formalista ni aislada teoría del derecho — «normativismo realista», es su título- siguiendo la diferenciada estela de los grandes maestros H. KELSEN, H. HART y N. BOBBIO.

Y por otro lado, la faceta crítica, con la apreciación de que la teoría de la justicia, espacio donde se debate y argumenta sobre las decisivas cuestiones de la legitimidad y la justificación del derecho y del poder, constituye parte fundamental ineludible de la filosofía jurídica: y, como digo, el puente imprescindible de ésta con la filosofía política y con la filosofía moral. Hay que señalar enseguida, en coherencia con lo que se viene 
afirmando aquí (y con mi plena concordancia), que para el profesor PECES-BARBA el contenido básico de tal filosofía de la justicia es precisamente los derechos humanos. Aquellos derechos — resaltemos_ que vinieron a ser positivizados, legalizados, como detallados derechos fundamentales en nuestra Constitución, en cuanto concreción de los mencionados valores y principios, gracias en amplia medida a su firme personal insistencia dentro de la alta Comisión (bien acompañado desde la izquierda) como título I, arts. 10 a 55 de la misma. Desde otras posiciones políticas, recordemos, se prefería sobre ello un simple reenvío a los textos y declaraciones internacionales. Tales derechos derivan, como depurado resultado histórico y propuesta crítica racional, del mundo moderno y de la más autocrítica Ilustración expresados en la tríada ética y política de la libertad, la igualdad y la fraternidad (solidaridad). De ahí procede, no sin cambios ni conflictos de todo tipo, la «ética pública» — definía nuestro amigonecesaria de seguir construyéndose hoy en libertad y democracia sobre la base de las fuertes exigencias de carácter universal que definen a la dignidad humana. Para todas estas importantísimas cuestiones tenemos, entre otros, sus libros y monografías sobre Derechos fundamentales (1973, con sucesivas nuevas ediciones), Los valores superiores (1984), Ética pública y derecho (1993), o La dignidad de la persona desde la filosofía del derecho (2002).

Fueron frecuentes y desde hacía mucho tiempo los trabajos de G. PECES-BARBA sobre unos y otros de esos derechos fundamentales, o sobre aspectos concretos de los mismos, y asimismo (Instituto «Bartolomé de las Casas», por él creado) las tesis doctorales que profundizan en ellos bajo su dirección. Es verdad que todos asociamos enseguida su nombre al de los derechos humanos y los derechos fundamentales. Junto a sus propias investigaciones de contenidos más teóricos e históricos habría que mencionar aquí también, ahora como director, la monumental obra colectiva Historia de los derechos fundamentales, en nueve volúmenes (desde 1998). Pero al lado de ello, como ya señalé, puede muy bien decirse que en su filosofía política está siempre presente de manera muy prevalente su insistencia por la radical necesariedad, el carácter imprescindible del marco institucional y procedimental (democrático) en que como Estado de derecho mejor podrán y habrán de hacerse efectivas esas exigencias de protección y realización de los derechos fundamentales para todos los ciudadanos, entendida esta expresión de la ciudadanía en su sentido más amplio posible. La razón de ser del Estado de derecho es, así, precisamente la protección jurídica y la realización efectiva de esos, siempre en evolución, derechos fundamentales y constitucionales.

Soberanía popular como poder constituyente y como poder constituido (en sus diferenciadas manifestaciones e intervenciones), libertad crítica y de expresión, sufragio universal, regla de las mayorías, respeto a las minorías, voluntad de consenso, el ser humano como agente moral, doble participación en decisiones y en resultados, importancia básica de la cohesión e igualdad social, primacía del Parlamento como sede de la soberanía popular y, en consecuencia, función fundamental de las instituciones y de sus poderes ejecutivo y judicial (en división o separación, suele decirse, pero nunca aislados e incomunicados entre sí). Estos valores y principios constituyen también para él la base de la ya mencionada «ética pública» de la modernidad en su evolución hasta nuestros días. Y junto a otras decisivas derivaciones, son las piezas imprescindibles para esa siempre abierta realización de los derechos fundamentales (y hasta diríamos que de las éticas privadas) en el contexto del Estado social y democrático de derecho. 
Dentro de ese ámbito general, en su obra sobre La democracia en España, experiencias y reflexiones (1996), el profesor PECES-BARBA —al hilo de su propia autobiografía personal - vino a llamar especialmente la atención en la vida política de nuestro país en esos años (pero creo que valdría casi aún más para hoy) acerca de las deficiencias y patologías (no insalvables, ni incurables) de dos instituciones básicas para la democracia como son nada menos que el Parlamento y los partidos políticos. En otras obras posteriores volverá, como veremos, a una consideración más extensiva de las diferentes causas de esas y otras patologías. La referida ahora al Parlamento formulará una muy insistente propuesta, ante la debilitación injustificada o la pérdida innecesaria de algunas de sus importantísimas funciones, en favor de una necesaria recuperación de su supremacía y posición de centralidad en cuanto legítimo representante de la soberanía popular dentro de una adecuada organización de los poderes públicos en tal Estado social y democrático de derecho. Quien fuera su presidente entre 1982 y 1986 subraya que «hay que hacer un sitio, siempre preeminente, al Parlamento en la democracia del futuro que, como dice TOURAINE — cita aquél—, no será sólo la democracia de la representación y de la deliberación, sino la democracia de la liberación, que intenta generalizar la efectiva dignidad de todos los hombres». Es decir, en una democracia de doble participación - suelo señalar yo- en la toma de decisiones y en la consecución de resultados, propone aquél un consecuente y representativo Parlamento que sea, como siempre, de deliberación y, a la vez entonces y en el futuro, de verdadera liberación.

Y respecto a los partidos políticos, tan imprescindibles y de justificada legitimidad, pero a la vez con tan fuerte proceso de deslegitimación fáctica en las democracias actuales, PECES-BARBA avisaba ya entonces de los gérmenes de fondo y riesgos reales que desvirtúan su carácter y sus importantes tareas. Así, por ejemplo, el clientelismo personalista, el partidismo cerrado, la falta de democracia interna, la selección inversa o negativa, las dependencias económicas, la inamovible profesionalización, el excesivo culto al gran líder, la extralimitación de las funciones y poderes de aquellos, dando lugar a esa criticada partitocracia. Patologías, ésas y otras, ya dijimos, que sólo podrán entrar en vías de solución, complejas en todo caso, fortaleciendo su progresiva democratización y libre crítica interna y un mucho mayor y abierto contacto con la sociedad civil, y con los nuevos movimientos sociales (le señalaba yo), en evitación de su anquilosamiento y dogmatismo burocrático. Junto a otras medidas más concretas bien vistas por aquél (cambios en las leyes electorales, formación de listas mucho menos subordinadas a la jerarquía partidaria, oposición al sistema absoluto de cierre y bloqueo, etc.), una buena solución — piensan muchos- iría asimismo por el paso progresivo del modelo tradicional de partido de «militantes» (no muy grato vocablo) a un mucho más abierto partido de ciudadanos, es decir, de contrastados votantes y coherentes simpatizantes. Concuerdo en gran medida con ello, más aún cuando en ciertas desgraciadas circunstancias (antiterrorismo de Estado, corrupción, aislamiento de la sociedad, falta de sensibilidad intelectual) me he visto impelido a declararme repetidamente en público y en privado, medio en broma, medio en serio, como «militante, no simpatizante».

Todos estos mencionados valores, principios, derechos y hasta los consecuentes procedimientos e instituciones para alcanzar y potenciar aquellos, forman pues parte 
de la que se identifica hoy —ya se ha dicho aquí- como ética pública. «Quiero así decir - escribía G. PECES-BARBA, conectando en esa doble participación la inicial libertad fáctica de elección y la final autonomía o libertad moral (Ética pública y derecho, 1993) — que en este punto de vista del paradigma de ética pública de la modernidad, la libertad inicial o de elección tiene - subraya aquél — una organización política y jurídica, inspirada y fundada en el valor de la libertad social, a la que completan y matizan, la seguridad, la igualdad y la solidaridad, que permite llegar a las personas a abordar el ideal de la autonomía o libertad moral». Ética pública incluyente, pues, que en su propuesta hasta incluiría (cuestión siempre debatida) a los excluyentes, al menos a los no violentos. Ésta es la grandeza de la ética pública democrática —señalaba aquélque, por supuesto, en modo alguno se retrae ante la institucionalización en el Estado de derecho de los consecuentes mecanismos - incluso penales- de eficaz y legítima autodefensa. Dicha ética pública sería, así, resultado histórico y producción crítica racional, sometida a su vez a los propios controles internos y externos, en proceso de derivación constante y coherente desde una teoría de la justicia basada en esos valores de la libertad real para todos y de la autonomía moral personal en el marco hoy del Estado social y democrático de derecho.

\section{LA ESPAÑA CIVIL: EL INTELECTUAL Y EL POLÍTICO}

Toda esta «teoría general» que identifica de manera un tanto esquemática la filosofía jurídico-política del profesor G. PECES-BARBA (se trata en efecto de una muy sucinta y fragmentaria síntesis vista desde mi propia, pero en gran parte compartida, perspectiva personal) se ha elaborado tomando siempre por él como referencia teórica y práctica la concreta circunstancia histórica de este país en ese largo tiempo que va desde la lucha contra la dictadura franquista a la construcción de la actual España democrática. Y lo ha plasmado —uniéndolo una vez más a su propia biografía - en el que, a título individual, podría considerarse como su último libro (La España civil, 2005) donde también se resumen y revisan las claves de sus propuestas intelectuales y políticas de siempre pero con no pocas aportaciones nuevas pensando más aún en el presente y el futuro colectivo (con posterioridad a él aparecería en 2007 la obra de los profesores de la Universidad Carlos III, por él dirigida, Educación para la ciudadanía y derechos humanos, básica para la buena teoría y la democrática política legislativa sobre esta tan debatida y atacada cuestión).

En esa obra de 2005, dedicada a «la memoria de Antonio Machado, Fernando de los Ríos y Manuel Azaña, apóstoles de la España civil», escribe por su propia parte G. PECES-BARBA: «La España civil expresa una voluntad muy firme de contribuir con mis ideas al futuro de nuestro país, señalando los rasgos de una sociedad bien cohesionada. Es una obra reformista y moderada» —añade— donde «presento un modelo que me parece viable y posible; no es una utopía irrealizable, sino un proyecto difícil, aunque no imposible. Es una utopía reformista que puede hacerse realidad. Me considero - manifiesta aquél- un socialdemócrata, un socialista liberal que rechaza el extremismo, el fanatismo y la imposición». Tal filosofía jurídico-política democrática, con sus valores y principios, instituciones y procedimientos, fortalecidos en comunidad con Europa, constituyen — dice allí PECES-BARBA— los cimientos, «los pilares de 
la España civil». Los mismos — concluye aquél vinculando ambas perspectivas- que «constituyen la ética pública recogida en la Constitución Española y que deriva como fundamento último de la idea de dignidad humana».

El punto de vista ético y el punto de vista sociológico — se señala allí recuperando la dimensión histórica de uno y otro- fueron logrando buenas coincidencias genéricas, aunque siempre a su vez con graves insuficiencias por ambas partes, vistas en el ámbito de la modernidad: por ejemplo, juntando aquí lo positivo y lo negativo, la afirmación del humanismo, la autonomía moral y la racionalidad versus las muy fuertes desigualdades sociales internas y la violenta explotación colonial internacional. No faltaron tampoco perversas justificaciones de estos grandes males desde posiciones naturalistas y mecanicistas propias después del peor hedonismo y predarwinismo. Proponiendo superar tal dualismo y disensión histórica y actual, que forma parte de las patologías de la Ilustración, asume el profesor PECES-BARBA su propia posición personal. Escribe así: «En el acervo de mis convicciones ideológicas o de ética pública se pueden distinguir tres momentos históricos desde los cuales — afirma- mi conciencia se ha ido formando: el Renacimiento y los humanistas y los libertinos, que están en el origen de conceptos como los de dignidad, felicidad o tolerancia; la Ilustración, en que surgen todos los nuevos ideales que van a acompañar el desarrollo de la dignidad, la Constitución, los derechos humanos, el Estado de derecho, la trilogía de la libertad, la igualdad y la solidaridad, la tolerancia y la paz; y, finalmente - subraya con este término y de manera especial-, el socialismo democrático, abierto a las corrientes moderadas de la satisfacción de las necesidades, de la búsqueda de la igualdad y de la solidaridad, así como a los nuevos valores del medio ambiente y partiendo de la universalización de esos derechos». Esos tres momentos — como vemos- son sustancialmente aquellos que en su día asimismo invocaba entre nosotros Fernando de los Ríos (El sentido bumanista del socialismo, 1926) como germen y base de su concepción del mundo. G. PECES-BARBA siempre se identificaba más con él (incluso como «cristiano erasmista») que con el otro profesor filósofo socialista democrático más cercano a un cierto marxismo, Julián Besteiro, pese a haber sido éste y él mismo presidentes del Parlamento español, respectivamente en 1931 y en 1982.

A este respecto con alguna frecuencia nuestro buen amigo gustaba de explicitar los nombres propios individuales (me parece muy bien, yo también lo hago) de los ilustres por los que, dentro de esas y otras corrientes históricas de pensamiento, se considera, en mayor o menor medida, influido. Aparecen allí los que serían, pues, sus mejores polos de referencia: entre los clásicos Platón, ARISTÓTELES, CiCERÓN, SÉNEca, Santo Tomás, Giordano Bruno, Suárez, Vives, Montaigne, Erasmo, Grocio, Descartes, Spinoza, Locke, Leibniz, Voltaire, Diderot, Rousseau, Condorcet, Montesquieu, Paine, Tocqueville, Stuart Mill, Blanc, Hegel, Comte o MarX, «a mi juicio — señala aquél- los más relevantes hasta el siglo XX». Sin pretender ser exhaustivas, me extraña de todos modos la ausencia de I. KANT en estas listas, aunque sea cierto que en otros pasajes más sistemáticos de sus obras venga invocado. Entre las gentes del XIX y XX recupera en diferentes ámbitos a WEBER, HuSSERL, BERGSON, E.-A. Charrier — conocido como Alain—, E. Bernstein, G. Solari, P. Gobetti, H. KelSEN o J. MARITAIN; más recientemente J. RAWLS, R. DwORKIN y, sobre todo, N. BOBbIO. Entre otros autores españoles del siglo XX, el iusfilósofo PECES-BARBA se reconoce de manera particular en F. DE los Ríos, P. Dorado Montero, G. DE Azcárate, L. 
JimÉNEZ DE AsÚA; ya contemporáneos suyos, F. GonZÁLEZ ViCÉn, J. RuIZ GimÉNEZ y (generosa pero sé que sinceramente) él siempre añadía E. Díaz.

Pero, además — como vemos - de profesor de filosofía jurídica (ética y política), además de un teórico y un intelectual comprometido, de todos es sabido, G. PECESBARBA fue también un político: como tal ejerció de manera muy influyente y activa hasta 1986, pero reservada y potencialmente siguió siéndolo hasta el final de sus días. El intelectual y la política: pocas de las gentes de su generación podrían representar mejor que él esa efectiva dedicación y vocación hacia estas dos tan decisivas e imprescindibles tareas que, de manera especial, en la España de todo este nuestro tiempo se han dado tan íntima, testimonial y fructíferamente relacionadas. No ha sido aquél un político que como tal optara por prescindir de su filosofía, de la necesidad de coherencia teórica y fundamentación ética. Ni ha sido un profesor - como muy principalmente siempre se reconocía él一, que, en diferentes momentos, haya rehusado estar incluso en primera línea de la práctica política; se desdoblaba y compatibilizaba muy bien ambas dimensiones, siempre ayudado y secundado en tan diferentes tareas por leales y eficaces equipos de colaboradores. El profesor de filosofía del derecho fue así sucesivamente diputado desde 1977, secretario general del grupo parlamentario socialista, miembro destacado —ya se ha dicho aquí- de la ponencia que elaboró la Constitución de 1978 y, finalmente, presidente del Congreso de los Diputados de 1982 a 1986.

Como es bastante lógico y normal que ocurra en relación con esos u otros dualismos de carácter personal, no ocultaré aquí en estas notas (biográficas, para nada hagiográficas) que entre sus críticos más severos algunos le consideraban tal vez por su aptitud para las relaciones públicas, su capacidad de trabajo o sus dotes organizativas, incluso conspirativas, es decir, como político práctico pero no estrictamente (a mi juicio, de modo en exceso estricto o, incluso, distorsionado) por sus creaciones iusfilosóficas. Otros, en cambio, poniendo en cuestión su talante de auténtico político (por no transigir, sino imponiendo sus propios criterios, ante determinadas decisiones públicas, incluso institucionales, invocando razones morales o jurídicas, recuérdese que con frecuencia se le acusaba de «juridicista»), sin embargo le reconocían y ensalzaban - ¿puente de plata? - por sus méritos como profesor y después como rector (y creador) de la Universidad Carlos III de Madrid. Aparte de ello, es obvio que sus «enemigos», que los ha tenido, le negaban sin más y a la vez con contumaz ignorancia y malevolencia ésas y cualquiera otra de sus cualidades personales, intelectuales o políticas. Esto es algo que por desgracia se puso indignamente de manifiesto en amplios sectores de la derecha política y mediática con agresividad y aversión inusitada hacia él con ocasión de su nombramiento en 2004 como «Alto Comisionado de Apoyo a las Víctimas del Terrorismo».

Sé que G. PeCEs-BARBA se sentía muy identificado (como, por lo demás, también el autor de estas páginas) con las reflexiones y el modelo propuesto por nuestro común maestro N. BobBio para el buen entendimiento de esa relación con tensión entre el intelectual y la política: las ha expuesto éste en diferentes momentos y escritos suyos pero principalmente en su obra Il dubbio e la scelta. Intellettuali e potere nella societá contemporánea (1993). Señalaba allí N. BoBBio que la particular actitud prescriptiva y optativa que define al intelectual, como hombre de cultura, se halla en su base firmemente radicada en los propios factores y valores que hacen posible, más fiable y 
segura, la vida intelectual misma, la existencia y subsistencia de la cultura: son éstos el estudio, la indagación científica, la argumentación racional, la pluralidad crítica, la libertad para discrepar, el diálogo con la comunidad científica, etc. Pero, a su vez, hacia observar (también KELSEN, recuérdese, al tratar de su concepto de justicia) que todo ello constituye la base de lo que entendemos por democracia, por convivencia pacífica, libre y civil tan reclamada siempre para España por G. PECES-BARBA y de nuevo en este libro sobre La España civil.

De este modo N. BobBio subrayaba de manera consecuente que a los hombres de cultura les corresponde una tarea eminente en defensa de las condiciones básicas que permiten precisamente la supervivencia misma y el desarrollo de un mundo civil. Y unida a ella —-dando un paso más_ el compromiso (la responsabilidad) de actuar para la defensa efectiva de las condiciones y los postulados reales de la cultura. Desde esas condiciones y postulados básicos y de fondo, la filosofía política del maestro italiano se orienta de modo coherente a posiciones personales sobre las que hay general consenso en calificar —así lo hace también él— como muy concordes con el denominado socialismo liberal. $\mathrm{O}$ - como yo más bien puntualizaría, entre otras cosas, por su insistencia en la importancia de la igualdad y de la presencia del Estado — como más identificadas con lo mejor de la socialdemocracia y, sin entrar aquí y ahora en mayores diferenciaciones, con el propio socialismo democrático. Recuérdese que para N. BobBio (Destra e sinistra. Ragioni e significati di una distinzione politica, 1994; traducción española, 1995) la igualdad es precisamente la nota que caracteriza a la izquierda y que —en una u otra graduación cuantitativa - expresa la diferencia cualitativa con la derecha. Como actitud seriamente asumida, con éstas y otras mencionadas influencias, como político e intelectual G. PECES-BARBA vino siempre a identificarse dentro de esas muy concordantes características socialistas.

\section{LAS PATOLOGÍAS DE LA DEMOCRACIA. POR UN SOCIALISMO LIBERAL}

En esta perspectiva de un socialismo liberal, con el cual, junto al de socialismo democrático, prefería identificarse él, y en relación con sus referidas propuestas de presente y de futuro para una España civil y laica, PECES-BARBA va a resaltar y a estructurar la parte crítica de este su libro de 2005 en torno - dice- a tres patologías de la democracia que ahora, incluso en los últimos tiempos después de su muerte, han adquirido entre nosotros una aún mayor y más grave actualidad. Son —escribe aquél- los «principales obstáculos que identifico — señala — con tres cuestiones: el nacionalismo, porque no acepta la idea de España; la Iglesia, entendida como institución, porque no acepta plenamente lo que significa la democracia; y la derecha política, representada por el Partido Popular, porque no acepta en toda su profundidad, pese a los más de veintisiete años de arraigo, las bases fundamentales con las que se construyó el consenso, el gran pacto social [...] que hizo posible la Constitución de 1978». Son, como se ve, observaciones que más allá de sus derivaciones de carácter coyuntural, las que aquél denomina como «patologías de la autonomía, de la autoridad y de la crispación», reenvían a cuestiones muy de fondo que son, cada una de ellas, amplia e intensamente debatidas en la filosofía política actual. 
a) Sobre la primera — nacionalismo como exacerbación de la autonomía en el actual Estado constitucional - con riesgos, dice, de dar lugar a una ilegítima «patología de la autonomía», de carácter soberanista y secesionista, en definitiva, de minorías que pretendan imponerse a las mayorías, la posición de G. PECES-BARBA (descontando algunos excesos y desajustes verbales de carácter ocasional) está bien clara. En todo caso los Estatutos, las reformas estatutarias de las Comunidades Autónomas y, por supuesto, los poderes derivados de aquellos, tienen que respetar los límites y procedimientos de la Constitución así como las competencias exclusivas del Estado. Proponer, los tales poderes, la ilegal desobediencia a la Constitución, obrar a sabiendas en contra de ella, implica autorizar a los demás órganos institucionales a hacer lo propio (situación, diríamos prehobbesiana) socavando toda democrática legalidad y legitimidad. Los Estatutos, normas institucionales básicas de las Comunidades Autónomas, están autorizados por la Constitución, ya que emanan de ella. Ésta es —insiste- la norma fundamental básica del conjunto del sistema que autoriza y es responsable del resto del ordenamiento, incluidos los Estatutos. Y ése es el marco en el que, por de pronto, ha de situarse toda invocación (no se olvide que por unos u otros) del legítimo «derecho a decidir».

Por otro lado, sigue aquél, si se asume el título de «comunidades históricas», éstas no habrían de reducirse a las que ya habían puesto en marcha su Estatuto durante la Segunda República (aunque a su vez pudieran aducirse razones históricas para ello) sino que lo reivindica también para otras, quizás para todas, pues — recuerda— entre todas ayudaron a identificar a una de las primeras naciones y de los más viejos Estados de la Europa moderna. Respecto a España como nación, acuña G. PECES-BARBA la idea de España como «nación de naciones» (algo, pues, muy diferente al mero «Estado plurinacional»), en la cual los planteamientos soberanistas y los proyectos separatistas — dice- carecen de sentido. No tendrán además apoyos suficientes en esta sociedad y en el seno de Europa, una Europa que es ya de los Estados y de los ciudadanos y que no deja espacio para derechos colectivos ni para identidades cerradas. La nación española — concluye aquél— era el poder constituyente y, por consiguiente, previa a la Constitución. Las otras naciones se reconocían jurídicamente en la Constitución. Culturalmente tenían también una existencia anterior, pero su juridificación se produce desde la entrada en vigor de la Carta Magna.

Puedo concordar en gran parte con las posiciones de PECES-BARBA, sobre todo en la que fue fundamental condena absoluta del terrorismo y, en cualquier caso, la afirmación de la libertad para el pacífico disidente proveniente de allí. Pero yo también recomendaría (todavía Ortega y Gasset) «conllevar» serenamente en nuestros días, con mayores dosis de realismo, de diálogo y de esperanza activa, la existencia fáctica de tales nacionalismos. Para así buscar hoy vías de solución a nivel político - la cuestión es de largo recorrido- con su posible incardinación explícita en un Estado federal que, por lo demás, en cuanto a competencias no estaría — pienso- muy lejano de un evolucionado Estado actual de las Autonomías. Y para un tiempo futuro quizás podamos ir a la integración y progresiva «disolución» y pérdida de sentido en Europa de todos los actuales radicalismos nacionalistas de ese carácter soberanista.

Digo esto sin poder olvidar a la vez, en la filosofía política y social, las connotaciones más bien conservadoras, incluso en ciertos casos explícitamente reaccionarias de 
unos u otros de esos nacionalismos. Son los derivados por lo general (siglos XVIII-XIX) de ciertas concepciones historicistas (ejemplo el mismo SAVIGNY) y de algún romanticismo no liberal donde se sueña como místico e irracional el alma de los pueblos y de la misma historia, es decir, donde lo real se hacía y se veía como racional precisamente para que - como desvelaba el MARX hegeliano- lo racional pudiera hacerse real (reenviaría aquí al capítulo II de mi libro de 1966, Estado de derecho y sociedad democráti$c a$, en radical oposición a los idearios totalitarios inspiradores del otro no «periférico» nacionalismo, el del régimen franquista, por todos definido, según se configuraba por él mismo como nacional-catolicismo).

b) El segundo para PECES-BARBA de esos principales obstáculos a la pretérita, actual y futura España civil y laica es, ya veíamos, «la Iglesia, entendida como institución, porque — dice - no acepta plenamente lo que significa la democracia». Frente a ese obstáculo está, por de pronto, la crítica a toda teocracia, pero también hoy al fundamentalismo religioso y/o teológico que pretende imponer su dogma, su verdad (para ellos verdad absoluta), incluso en y frente a las sociedades democráticas y sus libres decisiones públicas, políticas y jurídicas. Como profesor y estudioso de estas cuestiones, aquél también ha dedicado frecuentes trabajos en revistas especializadas y en artículos periodísticos contra esa que llama «patología de la autoridad» (yo preferiría decir «patología de la verdad») referida muy en especial a la Iglesia católica. La ejerce ilegítimamente ésta, cuando sus jerarquías y sus seguidores políticos —en línea con el actual «fundamentalismo teocons»—- sostienen que en el Parlamento no se pueden debatir ciertos temas, ni aprobar ciertas leyes, por entenderse que son contrarios a la verdad por aquella considerada como dogma intangible y como norma moral inmutable, eterna y natural. «En la actualidad — repetía siempre PECES-BARBA— se trata de temas como el divorcio, la eutanasia, el aborto o el matrimonio entre homosexuales, pero en el siglo XIX lo eran entre otros, el derecho de sindicación, el sufragio universal o la libertad de expresión y de conciencia». Recuérdese el Syllabus de Pío IX (1864) o el libro del presbítero F. SARDÁ I SALVANY, El liberalismo es pecado (1884), con nueva edición crítica (en los dos sentidos de la palabra) de S. HibBS-Lissorgues. Sobre Pío IX y su tiempo véase ahora publicada, en 2000, la sugerente obra de F. SOSA WAGNER.

Ésta es la tesis que, puede decirse, en líneas generales ha mantenido la Iglesia durante toda la Edad Media e incluso en la Edad Moderna, en clara oposición con el espíritu de la Ilustración. Se trata en definitiva de un iusnaturalismo teológico (y ontológico), basado en la triada jerárquica de ley eterna, ley natural y ley positiva, definidas siempre éstas por los poderes eclesiásticos, explícitamente opuesta tal doctrina a los caracteres propios de la democracia entendida, entre otras exigencias éticas y políticas, como libre expresión de la soberanía popular. Se volverá aquí sobre ello más adelante. Recordemos que, entre nosotros, G. PECES-BARBA se opuso con decisión y con toda razón a las pretensiones dogmáticas y antidemocráticas de semejante concepción que cercena sin más la libre soberanía popular.

En este punto lamento tener que constatar que la Iglesia católica no ha tenido el menor reparo ni prudencia alguna para condenar nominatim y de modo directo y explícito a nuestro amigo, todo hace pensar que a causa de esa su actitud crítica y democrática en defensa de la España laica y civil. Lo ha hecho ahora en concreto, días antes de la muerte de aquél, nada menos que a través de una muy alta jerarquía del Va- 
ticano, en la solemne carta oficial emanada — así reza el texto- por «Tarcisio cardenal Bertone, secretario de Estado de Su Santidad» el pasado 11 de julio de 2012, quizá a instancias de la propia Conferencia Episcopal Española. En dicha misiva cardenalicia, carente de la más mínima consideración y respeto, se menciona al «señor G. PECESBARBA» (es decir, a quien fue catedrático de filosofía jurídica, moral y política de la Universidad Carlos III de Madrid, fundador y primer rector de ella, Presidente del Congreso de los Diputados del Estado español) como una de las personas que dan pretexto a la «perplejidad» y reacción contraria del Vaticano frente los «reconocimientos» habidos a aquél, a causa de su otorgamiento del doctorado Honoris Causa, por la Pontificia Universidad Católica del Perú prohibiendo a ésta seguir utilizando los títulos precisamente de Pontificia y Católica. A los profanos, no expertos en esos asuntos eclesiales, todo esto nos suena a lo que otrora (y aquí, en nuestro país no tan otrora) hubiera sido sin más una especie de «anatema», de formal o informal «cédula de excomunión», aunque ahora ya sin pasar el encausado al poder del «brazo secular» (vid., con toda razón y fundamentación histórica el artículo del profesor J. SAUQUILLO sobre «La implacable "jurisdicción” de la Iglesia Católica», en Cuartopoder, 9 de noviembre de 2012).

Pero más allá de estos dogmatismos religiosos o patologías de la «verdad», la cuestión de fondo que siempre y también aquí se plantea, desde perspectivas muy diversas e incluso radicalmente contrarias, es la que hace referencia a la formulada como exigencia de «límites y limitaciones» de las mayorías y, por tanto, de la propia democracia. Sobre ello contestaba con contundencia PECES-BARBA: «Pero eso no es posible; no hay cotos vedados, ni política ni jurídicamente, a la deliberación por mayorías que no sean los que están en normas superiores (principio de jerarquía) o en materias para las que no está habilitado el órgano que pretende deliberar (principio de competencia)». Estimo que aquél está del todo en lo cierto cuando habla, como es su caso, en términos políticos y jurídicos en el marco de soberanías y/o mayorías ya constituidas, es decir constitucionales. Sin embargo, cuando se plantea con mayor radicalidad la cuestión de esos límites no sólo política y jurídicamente sino desde el punto de vista ético y en un marco constituyente - en él es donde, me parece, se sitúa nuestro común amigo E. GARZÓN VALDÉS cuando habla de «coto vedado» (cláusula que con todo yo también evitaría, prefiero la de «ciudad libre o abierta»)—, entonces no cabe duda que la tal cuestión se hace más compleja exigiendo otras imprescindibles y complementarias argumentaciones. Reenvío aquí a mi escrito titulado precisamente «Entrada libre en el “coto vedado"», en el núm. 30 de Doxa (2008) en Homenaje a Ernesto Garzón Valdés. Yo casi lo dejaría aquí recordando lo siguiente: que mejor que de «límites» o «limitaciones» de la democracia — tan arteramente pregonados y aprovechados por muchos limitadores que nunca limitan a las dictaduras- yo preferiría hablar, digamos, de exigencias coherentes o, mejor, de imperativos de coherencia con los mismos principios éticos y políticos - así como con las posteriores secuencias de derivaciones en derechos humanos- que definen y justifican a las democracias. Con ello, por supuesto, que para nada pretendo yo dar por definitivamente zanjada la discusión ni, mucho menos, resuelto sin más el fondo último de la cuestión.

Como base de ese imperativo estaría — y esto me parece lo fundamental— la afirmación del valor prioritario de la autonomía moral individual, del ser humano como agente moral, en definitiva de la libertad (tomada en serio) sin la cual nada es posible, 
tampoco la igualdad. Así, pues, como exigencias y derivaciones inmediatas, la libertad pública de expresión, de crítica, de deliberación, de participación tanto en decisiones (con libres elecciones y correspondiente representación parlamentaria...) como en resultados (de carácter social, económico, cultural...). La difícil y muy responsable valoración ética y política del cumplimiento, más o menos gradual, de tales exigencias o imperativos (llámensele, si se prefiere, derechos humanos), reconozcámoslo así, habrá de quedar otra vez ineludiblemente en manos de la entera comunidad, no de iglesias, institutos armados o grandes poderes económicos. Sobre esas bases, tal comunidad, que, no se olvide, se compone a su vez pluralmente de mayorías y minorías en relaciones de compleja interacción, actuaría ya en dicha posición incluso como hipotético nuevo poder constituyente.

Lo que sí es cierto, en cualquier caso, es que una dictadura que, supongamos, quisiera legitimarse y justificarse por su hipotético origen en elecciones democráticas (es el caso tan alegado de la llegada al poder de Adolf Hitler en la Alemania de 1933), tendría forzosa, es decir, coherentemente, que respetar —en su ejercicio- esas básicas e insuprimibles libertades y de modo especial tendría que seguir alimentando esa misma génesis legitimadora, por ella misma alegada, para que pudiera seguir considerándose como tal (democracia). Tendría que permitir la libre crítica (en la calle y en los medios de comunicación), tendría que existir un reconocimiento legal de la oposición política (partidos, sindicatos etc.), tendría que seguir convocando periódicas y regulares elecciones libres, etc. Eso no pasa en las dictaduras: lo que de verdad hay en ellas, incluso en esos casos tan frecuentemente citados, es un golpe de Estado dado por el propio Estado. Aquellas exigencias, imperativos de libertad son, en consecuencia, quienes definen e identifican a la democracia. Los llamados «límites», las «limitaciones» (si se prefiere utilizar estos términos) derivan única y exclusivamente de la insuprimible autonomía moral de — reitero, esto es lo fundamental— la conciencia individual, del ser humano como agente moral y, desde ahí con mediaciones a debatir, de la coherencia interna de la democracia misma.

c) Junto a esas dos mencionadas «patologías», de la «autonomía» y de la «autoridad» como las denominaba PECES-BARBA, la tercera de las que se presentan como obstáculos a la democracia viene asignada a la «derecha política», que aquí y ahora está «representada — dice bien- por el Partido Popular». Se la puede denominar, escribía aquél en 2005, siguiendo el anterior paralelismo, como «patología de la crispación» frente al espíritu de consenso y de entendimiento que caracterizó a la transición y a la redacción de la Constitución. Sus fuertes críticas a esa derecha política y a su correlativo partido son una válida y muy justa respuesta, ya se indicó en estas páginas, a los ataques desleales, agresivos e indignos de que había sido víctima con motivo de su nombramiento en 2004 como «Alto Comisionado de Apoyo a las Víctimas del Terrorismo». Pero más allá de esta circunstancia, está la crítica de fondo a las connotaciones socioeconómicas muy conservadoras de esa derecha política, críticas a las que se refiere con alguna brevedad PECES-BARBA, desde el socialismo liberal, en su severa crítica al capitalismo del «todo vale», causa profunda de la tan creciente y corrosiva actual corrupción.

Lo que llama aquél «el enriquecimiento excesivo e injusto», que ha desempeñado — dice- un papel destacado para obstaculizar la implantación de una sociedad libre 
y bien cohesionada en nuestro país, es — señala — una ideología de la sociedad capitalista que florece en tiempos de dictadura pero que convive y puede desarrollarse también en la democracia. Este capitalismo sin límites, con la carrera consumista y el egoísmo de la gran acumulación de bienes y riquezas, hace imposible la igualdad y la solidaridad y por eso daña también la libertad, incluso la de los propios beneficiados. Con frecuencia G. PECES-BARBA, en su crítica a la simulación de la economía como moralidad, es decir, de la reducción de ésta a aquélla y de la superioridad de las reglas técnicas del mercado sobre las que derivan de la dignidad de la persona, se acoge al veredicto clave de F. DE LOS Ríos en su muy relevante obra, ya recordada aquí, sobre El sentido bumanista del socialismo. Escribía éste, en efecto, en 1926: «El problema de la justicia social no es un problema de la libertad sin límites, sino — puntualiza- de la libertad para las personas y de subordinación de las cosas a los fines humanos». Pero en el capitalismo — acusa- son «lo primero las cosas, después las personas»; lo propio del capitalismo es «desentenderse del carácter de hombre de quien se utiliza como mercancía, comprando su trabajo». Nada extraño, pues, la conclusión de que «capitalismo y humanitarismo son, en efecto, dos términos antitéticos, contradictorios; la oposición en ellos es — dice- esencial».

Resultará oportuno recordar aquí algunos otros textos de quien, junto a otros, es nuestro común inspirador, el socialista liberal y democrático F. DE LOS RíOS, también con el apoyo en las posteriores y valiosas investigaciones de V. ZAPATERO sobre él: «Así como el capitalismo ha significado - insiste DE LOS RíOS— la exaltación de la idea de libertad aplicada a los objetos económicos con el fin de hacer más fácil la servidumbre de los hombres, el socialismo en cambio representa el sometimiento de la economía a un régimen disciplinario para hacer posible un mayor enriquecimiento de la libertad de las personas». Ese «régimen disciplinario» se llamaría hoy necesaria regulación democrática de los mercados. Lo que en definitiva habrá que hacer con respecto del hombre es — reclama en efecto aquél— «sustraerle del mercado» y con respecto a las cosas «someter la vida del mercado a las exigencias del interés general». El juicioso institucionista y el cristiano erasmista, que se integraban y formaban parte asimismo de su talante socialista, era muy duro en estas cuestiones: «Toda la política del imperialismo económico —escribía en ese su libro, recordemos de nuevo, publicado en 1926- ha consistido precisamente en apoderarse de los pueblos económicamente para poder justificar después el intervenir en su vida política» [...] «Tras los capitales — constata el "moderado" F. DE LOS Ríos- están, pues, los Gobiernos; tras los Gobiernos, los ejércitos». Su posición no es nada soft, nada debole, sino muy fuerte (para hoy): «Lo que afirmamos es que el capitalismo en sí mismo es una organización no de lucha, sino de guerra y, como tal, enemigo de la paz entre los pueblos».

No parece que hayamos inventado, construido, mejor vía para ir liberándonos de todo ello, para «someter la vida del mercado a las exigencias del interés general», para evitar su sacralización fundamentalista (de pretendida justificación científica) que la del Estado democrático y la sociedad democrática, es decir, el Estado social y democrático de derecho. Eran frecuentes las conversaciones y las concordancias con G. PeCES-BARBA sobre estas cuestiones. También para dar cuenta y razón, no nos olvidemos, del otro gran fundamentalismo de nuestro tiempo, el de carácter teocrático —antes tratado aquí- derivado del iusnaturalismo teológico tradicional. Por mi parte, últimamente vengo insistiendo en las coincidencias y la gran conjunción actual que de 
hecho forman esos dos fundamentalismos, el tecnocrático del mercado y el teocrático de la religión: coalición fundamentalista de neocons y teocons, por decirlo en la jerga política actual. Al lado de las diferencias objetivas y subjetivas entre ellos, lo que les vincula y unifica es, precisamente, su contumaz rechazo del Estado, muy en especial su recelo y aversión a las intervenciones del Estado democrático. A ello se aludía en el fondo, como hemos visto, de esas críticas de G. PECES-BARBA hacia las patologías de la autoridad (de la verdad dogmática) eclesial, del no entendimiento y de la exclusión social en el conservadurismo de esa derecha política que, aquí y ahora, él identificaba en el partido popular. Es bien conocido que no pocos neoconservadores, presuntamente liberales (en realidad liberistas), para nada le han hecho ascos a su colaboración con Estados autoritarios y dictatoriales. En cambio, esos recelos crecen y se manifiestan con mayor insistencia en el día a día y en las grandes teorías ante la presencia activa y las decisiones de las instituciones públicas de representación popular, es decir, ante los Estados de mayor contenido y formato democrático. El mercado - es decir, las intervenciones de sus gestores, grandes bancos y otras agencias financieras- es para ellos la gran panacea contra tal maldad estatal. Y aquél es, por tanto, quien debe restringir, debilitar o incluso suprimir -Estado mínimo - tal intervencionismo. El Estado, según ello, sólo debiera intervenir, en la conservación y custodia vigilante del orden (económico y demás) establecido precisamente desde su no intervención.

Con aún mayor claridad y rotundidad se alecciona por parte de las iglesias y en esos mismos términos discriminatorios contra las intervenciones del Estado democrático. Aquí no es necesariamente el omnipotente mercado quien subordina y debe subordinar al Estado democrático, sino la doctrina de la jerarquía eclesiástica que, ya lo veíamos, se define como encarnación de la ley eterna y de la misma ley natural. Pero tal conjunción fundamentalista se dobla y refuerza, como con frecuencia ocurre por ambos bandos hoy, cuando la «lex mercatoria» se identifica sin más con la ley natural. Cuando se predica que el orden natural consiste exclusivamente en dejar hacer, dejar pasar, y en no intervenir desde las instituciones públicas en defensa del interés general y, por tanto, de los intereses individuales que no tienen así otra mejor y más eficaz defensa (excepto sólo tal vez a través de la vieja caridad y de alguna más moderna filantropía). En cualquier caso, la jerarquía, el poder eclesiástico se autoproclama como supremo y dogmático censor, incluso querría ser soberano decididor, sobre aquello derivado de su propia moral, que, según ella, el Estado no puede hacer, de aquello de lo que el Parlamento no puede tratar ni de ese modo legislar. Tales legítimas intervenciones del Estado se convierten sin más para ella en ilegítimas intromisiones de las cuales aquél se debe abstener.

Desde estas bases hablamos aquí del fundamentalismo como actitud teórico-práctica propensa o, incluso, esencialmente ínsita en tal dogmatismo metodológico y epistemológico. Es decir, como definidora acrítica de una única y verdadera ortodoxia: bien sea fundada, desde siempre, en el fideísmo religioso (fundamentalismo teocrático), bien, en los tiempos actuales, producida desde instancias económicas con pretensiones ideológicas cientificistas (fundamentalismo tecnocrático). Según una u otra, la ley civil no puede, por razones obvias (orden de los grandes poderes económicos), alterar para nada los dictados del mercado; ni puede la ley civil legislar en lo no permitido por tal concepción religiosa y moral (eterna y natural). En ambos casos, también con ciertas diferencias objetivas y subjetivas entre ambas como ya quedó señalado, el resultado es 
la subordinación del Estado democrático, de la soberanía popular, a las absolutas necesidades de la determinación económica y a las, aún casi más absolutas, imposiciones de la potestad eclesial.

Es, pues, de suma importancia la crítica a esos fundamentalismos en su conjunción y efectiva coalición. Así como, por tanto, la recuperación y reconstrucción de las muy positivas funciones del Estado y el derecho, de las instituciones políticas y de una bien cohesionada y activa sociedad civil. Como señalaba también el ya antes recordado A. TOURAINE hoy el objetivo principal de la política teórica y práctica es «recuperar la capacidad de acción de un Estado debilitado — dice- desde hace dos décadas por el triunfo mundial del liberalismo»; y añade con rotundidad: «Por todas partes resurge la idea de la necesidad de las intervenciones del Estado». De lo que se trata, en definitiva, es de que la soberanía (oligarquía) del mercado no sustituya, subordine o anule a la soberanía (democrática) del Estado, es decir, del Estado social y democrático de derecho que es justamente lo que prescribe el art. 1.1 de nuestra Constitución. Todo ello, tales objetivos, que me parecen muy concordes con lo mejor del socialismo democrático, son los que — a mi juicio - han identificado de siempre a la filosofía jurídica, ética y política de G. PECES-BARBA.

Las derivaciones concretas de aquélla en su tarea como intelectual crítico y como político siempre activo, son las que veo yo — con más de cincuenta años de comunidad y amistad — como las grandes dimensiones de su vida pública, de su ética pública. Las que, junto a las de carácter más privado y personal, conformaban el complejo talante de quien más allá de la cercanía, afecto e incluso jovialidad para con sus gentes, también a veces se evadía y distanciaba de los demás cuando lo quería o lo necesitaba. Entonces evitaba tenazmente hablar de lo que no quería, de asuntos o cosas de diversa índole que le incomodaban o disgustaban. Tomando en consideración algunos de los rasgos de ese su carácter íntimo pero, sobre todo, del conocimiento de su personalidad pública, política e intelectual, en memoria suya, he querido yo concluir precisamente así este tan grato homenaje que en estos momentos han querido rendirle los comunes amigos y colegas de la tan prestigiosa revista Doxa. 